\title{
APLIKASI NANO EMULSI MINYAK SERAT SAWIT SEBAGAI PEWARNA ALAMI DAN SEBAGAI SUMBER KAROTENOID PADA MI BASAH PASTA PISANG AWAK (Musa paradisiaca var.awak) \\ Application of Nano Emulsion Palm Oil Fiber As Natural Dyes And Carotenoid Resources On Wet Pasta Noodles Awak Banana (Musa paradisiaca var.awak)
}

\author{
Hotman Manurung ${ }^{1}$, Rosnawyta Simanjuntak ${ }^{1}$ dan Franky Manurung ${ }^{2}$ \\ 1Program Studi Teknologi Hasil Pertanian, Fakultas Pertanian Universitas HKBP Nommensen Medan \\ 2Mahasiswa Program Studi Teknologi Hasil Pertanian Fakultas Pertanian \\ Universitas HKBP Nommensen Medan \\ manru_hotman@yahoo.com
}

\begin{abstract}
The attractive colors and colors derived from natural pigments are very much favored by consumers, as natural pigments in addition to being dyes also serve as a source of vitamins. The aims of this study were to determine the effect of the amount of nanoemulsion applied and storage duration on the color of wet banana noodles and the potential of wet noodles as a source of carotenoids and to increase the level of consumer acceptance of the color of wet noodles. The research used complete Random Design (RAL) factorial where first factor was the amount of nanoemulsion consisted of 3 levels namely: $0 \%, 3 \%$ and $6 \%$. Second factor was storage duration consists of 3 levels :0 days, 3 days, and 6 days. Each treatment with three replications. The results showed that the color of wet noodles ranged from yellowish to yellow. The intensity of the yellow color decreased during the storage process. The $3 \%$ nanoemulsion applied on wet noodles potentially suffice $4.4 \%$ of the vitamin A requirement and its potency decreased to $2.6 \%$ after the noodles were stored for 6 days. While noodles applied 9\% nanoemulsion on noodle was potentialto suffici vitamin A by $10,4 \%$ from requirement of vitamin A, but decrease to $4.3 \%$ after wet noodles were kept for 6 days. The storage duration gave no significant effect on the color preference test but the nanoemulsion application increased thelevel of panelist's preference on wet noodles color from 2.2 (dislikes) to 4.05 (like).
\end{abstract}

Key words: wet banana noodle, nanoemultion, colour, vitamin A

\section{A. PENDAHULUAN}

Warna merupakan salah satu faktor utama yang mempengaruhi seseorang memilih suatu makanan. Warna yang menarik dan warna yang berasal dari pigmen alami sangat disukai konsumen. Warna Karotenoid yang berasal dari tanam-tanaman merupakan salah satu dari jenis pewarna alami yang sering dimanfaatkan sebagai pewarna makanan (Rymbai, et. al., 2011). Saat ini sedang terjadi kecendrungan global untuk menggunakan pigmen alami sebagai pewarna pangan menggantikan pewarna sintetik. Kecendrungan ini dipicu berbagai publikasi dan studi empiris tentang bahaya dan penggunaan pewarna sintetik. Seperti penelitian Aini (2015) yang mengatakan dari 11 sampel mi basah yang diambil dari Pasar Tanjung Kabupaten Jember, ada enam sampel $(54,54 \%)$ menggunakan pewarna
Methanil Yellow. Pada hal sesuai dengan Peraturan Menteri Kesehatan Nomor 722/Menkes/Per/IX/88 tentang Bahan Tambahan Makanan Methanil Yellow dilarang digunakan sebagai zat pewarna makanan.

Salah satu keunikan minyak sawit dibandingkan dengan minyak nabati lainnya adalah jumlah dan jenis karotenoid yang terkandung di dalamnya. Rata-rata minyak nabati seperti minyak kedelai, minyak kelapa, dan minyak jagung mengandung karotenoid lebih kecil dari 100 ppm, sedangkan kandungan karotenoid CPO rata-rata 500-700 ppm (Choo, 2000). Scroeder, et al. (2006) mengatakan bahwa lebih dari $80 \%$ total karotenoid pada minyak sawit adalah karoten $\alpha$ dan $\beta$ yang berfungsi sebagai provitamin A dan penangkal radikal bebas. Potensi vitamin A (retinol equivalent) dalam minyak sawit 15 kali lebih 
besar di dalam wortel atau 300 kali dibanding tomat (Sundram et al, 2003).

Penelitian ini betujuan untuk mengetahui pengaruh jumlah nano emulsi yang diaplikasikan dan lama penyimpanan terhadap warna mi basah pisang awak dan potensi mi basah sebagai sumber karotenoid serta untuk meningkatkan tingkat penerimaan konsumen terhadap warna mi basah pasta pisang awak.

\section{B. METODOLOGI}

\section{Bahan dan Alat}

Bahan utama penelitian ini adalah pisang awak yang telah matang diperoleh dari Pasar Tradisionil di Lubuk Pakam dan terigu cap cakra kembar yang di peroleh dari Pasar Petisah Medan. Nanoemulsi minyak serat sawit diperoleh dari Laboratorium Oleo Pangan Pusat Penelitian Kelapa Sawit (PPKS) Medan.

\section{Pelaksanaan Penelitian}

Pisang awak yang telah masak pokok dicuci bersih lalu bagian daging buah pisang digunakan sebagai bahan baku. Bahan baku dipotong-potong sehingga mudah diblender. Diblender sampai bentuk pasta. Pembuatan pasta pisang sesuai dengan penelitain Safriani, dkk ( 2010). Pasta pisang yang dihasilkan dicampur dengan terigu sesuai dengan perbandingan 30 bagian pasta pisang dan 70 bagian terigu (Perbandingan pasta pisang dengan terigu 30:70 berdasarkan Manurung dan Simanjuntak, 2017). Berat campuran pasta dan terigu 500 gr. Pada saat pencampuran ditambahkan nanoemulsi sesuai dengan perlakuan yaitu $0 \%$ (kontrol, N0), $3 \%$ (N1), dan $6 \%$ (N2) dari berat campuran. Campuran tersebut diadon menjadi mi basah. Pembuatan mi basah tahap ke dua mengacu kepada Suyanti (2006) meliputi: pencampuran adonan, pengulenan adonan, pembentukan lembaran, pembentukan mi, perebusan dan pendinginan. Setelah dihasilkan mi basah, maka mi basah tersebut dikemas dalam kotak plastik putih (transparan) dan disimpan pada suhu dingin sesuai dengan perlakuan yaitu 0 hari (kontrol, L0), 3 hari dan 6 hari. Lalu dilakukan analisis mutu mi pisang awak yang meliputi: Uji warna (hue) mi basah, Analisis kandungan karotenoid, dan uji kesukaan terhadap warna.

\section{Analisis Parameter Mutu Mi Basah Pisang Awak}

a. Analisis warna Metode Hunter (Huching, 1999)

Sampel mi basah dihaluskan dengan blender, agar permukaan mi lebih rata dan tidak berongga. Sampel mi basah yang telah halus diletakkan dalam wadah cawan petri. Permukaan bahan diratakan, lalu dilakukan pengukuran nilai $L, a, b$. dengan menggunakan cromameter CR-400/410 yang sebelumnya telah distandarisasi. Sampel diukur dua kali dan setiap dilakukan pengkuran alat selalu distandarisasi. Lalu dihitung nilai ${ }^{0} \mathrm{Hue}$ dari nilai $\mathrm{a}$ dan $\mathrm{b}$ dengan menggunakan persamaan ${ }^{0} \mathrm{Hue}=$ $\operatorname{arc} \tan (\mathrm{a} / \mathrm{b})$. Deskripsi warna berdasarkan oHue dapat dilihat pada Tabel 1.

Tabel 1. Deskripsi warna berdasarkan ${ }^{\circ} \mathrm{Hue}$

\begin{tabular}{cc}
\hline${ }^{0}$ Hue $=\arctan (\mathrm{a} / \mathrm{b})$. & Deskripsi warna \\
\hline $18-54$ & Red $(R)$ \\
$54-90$ & Yellow Red $(Y R)$ \\
$90-126$ & Yellow $(Y)$ \\
$126-162$ & Yellow Green $(Y G)$ \\
$162-198$ & Green $(G)$ \\
$198-234$ & Blue Green $(B G)$ \\
$234-270$ & Blue $(B)$ \\
$270-306$ & Blue Purple \\
$306-342$ & Purple $(P)$ \\
$342-18$ & Red Purple $(R P)$ \\
\hline
\end{tabular}

Sumber: Hutching, 1999

\section{b. Analisis Kandungan Karotenoid}

Sampel mi basah terlebih dahulu diblender sampai halus. Lalu sampel ditimbang sebanyak $5 \mathrm{~g}$ didalam tabung reaksi. Ditambahkan heksan p.a sebanyak $10 \mathrm{~mL}$ ke dalam tabung reaksi dengan menggunakan pipet gondok. Divorteks selama 2 menit setiap 15 menit dalam 1 jam. Lalu disentrifuse selama 15 menit pada 3000 rpm. Layer atas dipipet dan digunakan sampel analisis karotenoid sesuai dengan prosedur PORIM, 1995.

\section{c. Uji kesukaan warna (Soekarto, 1998).}

Kepada panelist yaitu mahasiswa dan pegawai universitas HKBP Nommesen diminta pendapat tentang warna basah dengan melingkari atau mencontreng salah satu skala numerik seperti pada Tabel 2 di bawah. Jumlah panelist 20 orang. Skala numerik yang dilingkari atau dicontreng panelist dianalisis dengan uji sidik ragam dan perlakuan yang berbeda nyata diuji dengan uji beda nyata terkecil pada taraf $\mathrm{p}=0.5$

Tabel 2. Tabel uji kesukaan warna mi kering dan permen jeli 


\begin{tabular}{lc}
\hline \multicolumn{1}{c}{ Skala Hedonik } & Skala Numerik \\
\hline Sangat suka & 5 \\
Suka & 4 \\
Agak suka & 3 \\
Tidak suka & 2 \\
Sangat tidak suka & 1 \\
\hline
\end{tabular}

\section{HASIL DAN PEMBAHASAN}

Pengaruh Interaksi Jumlah Nanoemulsi dan Lama Penyimpanan terhadap Warna (Hue) Mi basah

Jumlah nano emulsi dan lama penyimpanan memberi pengaruh nyata $(\mathrm{p}<0,05)$ terhadap warna mi basah. Pengaruh interaksi nanoemulsi dan lama penyimpanan terhadap warna mi basah diuji dengan uji beda terkecil (BNT) seperti terlihat pada Tabel 3 di bawah ini.

Tabel 3. Uji beda jujur pengaruh interaksi jumlah nanoemulsi dan lama penyimpanan terhadap warna mi basah

\begin{tabular}{lccc}
\hline \multicolumn{1}{c}{ Perlakuan } & \multicolumn{3}{c}{ Lama Penyimpanan (hari) } \\
\hline $\begin{array}{l}\text { Jumlah pewarna } \\
\text { nanoemulsi (\%) }\end{array}$ & L0=0 & L1=3 & L2=6 \\
\hline N0=0 & $77,27 \mathrm{a}$ & $81,89 \mathrm{~b}$ & $83,69 \mathrm{~b}$ \\
$\mathrm{~N} 1=3$ & $86,09 \mathrm{c}$ & $87,50 \mathrm{~d}$ & $89,50 \mathrm{e}$ \\
$\mathrm{N} 2=6$ & $87,07 \mathrm{c}$ & $89,05 \mathrm{e}$ & $89,50 \mathrm{e}$ \\
\hline
\end{tabular}

Keterangan: Angka dalam tabel merupakan rataan dari 2 ulangan. Angka yang diikuti dengan huruf yang berbeda menunjukkan berbeda nyata pada taraf 5\%

Dari Tabel 3 terlihat bahwa terjadi peningkatan secara nyata $(\mathrm{p}<0.05)$ nilai hue mi basah selama penyimpanan baik pada N0, N1, atau pada N2. Peningkatan nilai hue berarti warna bergeser dari merah kekuningan ke warna kuning. Nilai hue terendah 77,27 pada N0 dengan lama penyimpanan 0 hari dan tertinggi 89,5 pada N1 dan N2 dengan lama penyimpanan 6 hari. Menurut Klaui dan Bauernfeid (1981) panas atau cahaya dapat mengubah komposisi karotenoid dan mengakibatkan perubahan stereoisomer yang secara alami berisomer trans menjadi isomer cis atau disebut fotodegradasi. Perubahan isomer trans menjadi isomer cis mengakibatkan intensitas warna merah berkurang mengarah warna pucat (Fikselova et al., 2008; Fabein et al., 2010). Kusumaningtyas dan Leenawaty (2009) mengatakan iosmerisasi karoten dari bentuk trans menjadi bentuk cis menyebabkan terjadinya penurunan intensitas warna. Namun secara keseluruhan warna mi basah sampai penyimpanan 6 hari adalah warna merah kekuningan. Deskripsi warna berdasarkan nilai
Hue 54-90 (merah kekuningan) dan 90-126 (kuning) (Hutching, 1999).

\section{Pengaruh Interaksi Jumlah Nano emulsi dan Lama Penyimpanan terhadap kadar Karotenoid}

Interaksi jumlah nanoemulsi dan lama penyimpanan memberi pengaruh nyata $(\mathrm{p}<$ $0,05)$ terhadap kadar karotenoid mi basah pisang awak. Pengaruh interaksi nanoemulsi dan lama penyimpanan terhadap penurunan kadar karotenoid diuji dengan uji beda terkecil (BNT) seperti terlihat pada Tabel 4 di bawah ini. Tabel 4. Uji beda terkecil pengaruh interaksi jumlah nanoemulsi dan lama penyimpanan terhadap penurunan kadar karotenoid

\begin{tabular}{lccc}
\hline \multicolumn{1}{c}{ Perlakuan } & \multicolumn{3}{c}{ Lama Penyimpanan (hari) } \\
\hline $\begin{array}{l}\text { Jumlah pewarna } \\
\text { nanoemulsi (\%) }\end{array}$ & $\mathrm{L} 0=0$ & $\mathrm{~L} 1=3$ & $\mathrm{~L} 2=6$ \\
\hline $\mathrm{N} 0=0$ & $0.00 \mathrm{a}$ & $0.00 \mathrm{a}$ & $0.00 \mathrm{a}$ \\
$\mathrm{N} 1=3$ & $2.15 \mathrm{c}$ & $1.15 \mathrm{~b}$ & $1.25 \mathrm{~b}$ \\
$\mathrm{~N} 2=6$ & $5.30 \mathrm{~d}$ & $2.15 \mathrm{c}$ & $2.10 \mathrm{c}$ \\
\hline
\end{tabular}

Keterangan: Angka dalam tabel merupakan rataan dari 2 ulangan. Angka yang diikuti dengan huruf yang berbeda menunjukkan berbeda nyata pada taraf 5\%.

Dari Tabel 4 diatas terlihat bahwa aplikasi nanoemulsi pada pembuatan mi basah pisang awak dapat meningkatkan kadar karotenoid dari $0 \%$ pada N0 (kontrol) menjadi 5,30\% pada aplikasi nanoemulsi sebanyak 6\%. Hal ini mengindikasikan nanoemulsi dapat digunakan sebagai sumber karotenoid pada pembuatan mi basah. Kadar karotenoid tertinggi terdapat pada mi basah dengan perlakuan N2L0 dan terendah pada perlakuan NOLO. Pada Tabel 4 juga terlihat semakin banyak jumlah pewarna nanoemulsi yang diaplikasikan maka jumlah karotenoid pada mi basah semakin meningkat. Sedangkan penyimpanan mi basah selama 6 hari mengakibatkan tejadi penurunan kadar karotenoid sebesar 41,86\% pada mi basah N1 dan sebesar $60,37 \%$ pada N2. Penurunan karoten akibat penyimpanan juga dikemukakan Oktora et al (2016) bahwa kadar $\beta$-karoten dari ekstrak kasar Dunaliella salina selama peyimpanan mengalami penurunan sebesar 15$20 \%$.

Penurunan kadar karotenoid selama penyimpanan disebabkan oleh adanya degradasi termal yang merusak karotenoid. Gaziano (1990) mengatakan struktur molekul karetonoid mempunyai ikatan ganda yang sangat mudah mengalami oksidasi secara acak 
sehingga dapat mengalami penurunan konsentrasi karotenoid. Kusumaningtyas dan Leenawaty (2009) mengatakan penurunan jumlah karetonoid disebabkan degradasi karotenoid melalui reaksi oksidasi yang menghasilkan lutein. zeaxantin dan $\alpha-$ zeakaroten. Semakin lama disimpan maka jumlah karotenoid yang teroksidasi menjadi lutein, zeaxantin dan $\alpha$-zeakaroten semakin banyak sehingga jumlah karotenoid menurun.

\section{Potensi Mi Basah sebagai sumber vitamin A}

Potensi mi basah sebagai sumber vitamin A didasarkan kepada 1: Asumsi berat/jumlah mi basah per sajian 125 gr; 2) Kebutuhan vitamin A untuk orang Indonesia dianjurkan rata-rata 500 retinolequivalen per hari atau $6 \mathrm{mg}$ karotenoid (Kartono et al., 2012); dan 3) Mengacu kepada FDA (2009) yang mengatakan bahwa suatu produk pangan dapat diklaim mengandung karoten tinggi apabila dapat memenuhi 20\% Angka Kecukupan Gizi vitamin A per sajian.

Berdasarkan asumsi dan kebutuhan vitamin A perhari maka potensi mi basah memenuhi kebutuhan vitamin A per hari dapat dilihat pada Tabel 5 di bawah ini.

Tabel 5. Potensi mi basah memenuhi kebutuhan vitamin A per hari (\%)

\begin{tabular}{ccc}
\hline \multirow{2}{*}{$\begin{array}{c}\text { Jumlah } \\
\text { nanoemulsi yang } \\
\text { diaplikasikan }\end{array}$} & \multicolumn{2}{c}{$\begin{array}{c}\text { Potensi mi basah } \\
\text { memenuhi kebutuhan } \\
\text { vitamin A per hari (\%) }\end{array}$} \\
\cline { 2 - 3 } & $\begin{array}{c}\text { Sebelum } \\
\text { disimpan } \\
\text { (L0) }\end{array}$ & $\begin{array}{c}\text { Setelah } \\
\text { penyimpanan } \\
\text { selama 6 hari } \\
\text { (L2) }\end{array}$ \\
\hline NO=0\% (kontrol) & 0 & 0 \\
N1=3\% & 4,4 & 2,6 \\
N2=6\% & 10,4 & 4,3 \\
\hline
\end{tabular}

Catatan: untuk menghitung potensi mi basah memenuhi kebutuhan vitamin A per hari dilakukan perhitungan sebagai berikut. Misalnya mi basah N1LO mengandung karotenoid 2,15 ppm atau 0,00215 mg/g. Diasumsikan jumlah mi basah per sajian/orang/hari sebanyak $125 \mathrm{~g}$. Maka mi basah N1LO yang beratnya sebanyak $125 \mathrm{~g}$ mengandung karotenoid sebanyak 0,27 mg. ( 0,27 mg = 4,4\% dari $6 \mathrm{mg}$ kebutuhan karotenoid yang dianjurkan)

Berdasarkan Tabel 5 tersebut di atas terlihat bahwa mi basah yang dihasilkan tidak ada yang berpotensi memenuhi $20 \%$ kebutuhan vitamin A per hari, sehingga mi basah yang dihasilkan tersebut belum dapat diklaim sebagai produk pangan berkarotenoid tinggi. Potensi tertinggi memenuhi kebutuhan vitamin A hanya 10,4\%. Pada Tabel 5 juga dapat dilihat bahwa potensi mi basah memenuhi kebutuhan vitamin A pada mi N1 mengalami penurunan dari $4,4 \%$ sebelum disimpan menjadi 2,6\% setelah disimpan selama 6 hari dan dari 10,4\% menurun menjadi 4,3\% pada mi basah N2. Penurunan potensi mi basah untuk memenuhi kebutuhan vitamin A disebabkan terjadinya penurunan karotenoid selama penyimpanan seperti dijelaskan sebelumnya.

\section{Pengaruh Aplikasi Jumlah Nanoemulsi dan lama penyimpanan terhadap uji kesukaan warna}

Jumlah nanoemulsi yang diaplikasikan memberi pengaruh nyata terhadap uji kesukaan warna, sedangkan lama penyimpanan memberi pengaruh tidak nyata $(p>0,05)$. Perlakuan yang memberi pengaruh nyata dianalisis dengan uji beda nyata terkecil seperti terlihat pada Tabel 6 di bawah ini.

Tabel 6. Uji beda nyata terkecil pengaruh jumlah aplikasi nanoemulsi dan lama penyimpanan terhadap uji kesukaan warna

\begin{tabular}{cccccc} 
Jumlah & \multicolumn{3}{c}{$\begin{array}{c}\text { Lama penyimpanan } \\
\text { aplikasi }\end{array}$} & \multicolumn{3}{c}{ (hari) } & & Rataan & $5 \%$ \\
\cline { 2 - 4 }$(\%)$ & 0 & 3 & 6 & & \\
\hline $\mathrm{N} 0=0$ & 2.2 & 1.65 & 1.95 & 1.933 & $\mathrm{a}$ \\
$\mathrm{N} 1=3$ & 3.6 & 3.45 & 3.45 & 3.5 & $\mathrm{~b}$ \\
$\mathrm{~N} 2=6$ & 4.05 & 3.8 & 4 & 3.95 & $\mathrm{c}$ \\
\hline
\end{tabular}

Keterangan: Angka dalam tabel merupakan rataan dari 2 ulangan. Angka yang diikuti dengan huruf yang berbeda menunjukkan berbeda nyata pada taraf $5 \%$.

Pada Tabel 6 terlihat bahwa semakin meningkat jumlah nanoemulsi yang diaplikasikan dari $0 \%$ (tanpa aplikasi nanoemulsi) menjadi $6 \%$ mengakibatkan uji kesukaan panelist terhadap warna mi basah meningkat dari skala 2,2 (tidak suka) menjadi 4,05 (suka). Hal ini disebabkan warna mi basah yang diaplikasikan dengan nanoemulsi mempunyai warna kuning cerah. Sedangkan warna mi basah yang tidak diaplikasikan nanoemulsi mempunyai warna putih pudar (tidak cerah). Hal ini disebabkan mi basah yang diaplikasikan nanoemulsi mempunyai warna merah kekuningan dan lebih cerah sehingga lebih menarik dibandingkan dengan tanpa menggunakan nanoemulsi. Rymbai et al (2011) dan Burrows (2009) mengatakan pemberian warna makanan terutama untuk meningkat daya terima konsumen. Warna yang cerah suatu bahan pangan menjadi identitas bahwa pangan tersebut berkualitas (Andarwulan, 2013), sehingga lebih disukai oleh konsumen. 


\section{KESIMPULAN}

1. Terjadi interaksi pengaruh jumlah nanoemulsi yang diaplikasikan dan lama penyimpanan terhadap nilai hue warna mi basah. Secara keseluruhan warna mi basah sampai penyimpanan 6 hari adalah kekuningan, namun intensitas warna kuning kuning berkurang sejalan dengan semakin lama mi basah disimpan.

2. Jumlah nanoemulsi yang digunakan sebagai pewarna mi basah pisang awak mempengaruhi potensi mi basah untuk memenuhi kebutuhan vitamin A. Mi basah yang menggunakan jumlah nanoemulsi sebanyak 3\% berpotensi mencukupi 4,4\% kebutuhan vitamin A dan potensinya menurun menjadi 2,6\% setelah mi disimpan selama 6 hari. Sedangkan mi basah yang menggunakan nanoemulsi sebanyak 9\% berpotensi mencukupi kebutuhan vitamin $\mathrm{A}$ sebesar 10,4\% dari kebutuhan vitamin A tetapi menurun menjadi $4,3 \%$ setelah $\mathrm{mi}$ basah disimpan selama 6 hari.

3. Aplikasi nanoemulsi sebagai pewarna $\mathrm{mi}$ basah dapat meningkatkan uji kesukaan warna. Semakin meningkat jumlah nanoemulsi yang diaplikasikan dari $0 \%$ (tanpa aplikasi nanoemulsi) menjadi 6\% mengakibatkan uji kesukaan panelist terhadap warna mi basah meningkat dari skala 2,2 (tidak suka) menjadi 4,05 (suka).

\section{DAFTAR PUSTAKA}

Aini, N. T.L. 2015. Analisis penerapan hygiene sanitasi industri mi basah " $X$ " dan pemeriksaan zat warna methanol yellow secara kualitatif. Skripsi Fakultas Kesehatan Masyarakat Universitas Jember.

Andarwulan, N. 2013. Stabilitas warna. Food Review. Vol. VIII No. 8: 28-32.

Burrows, A., J. D.2009. Palette of our palates: A brief history of food coloring and its regulation. comprehensive reviews in food science and food safety. Vol. 8:394408.

Choo, Y., M. 2000. Specialty Products: Carotenoids. Advances In Oil Palm Research Vol II. Editor: Yusof Basirun,
Jalani, B.s and Chan, KW. Malasya Palm Oil Board. Page: 1036-1060.

Fabein, D. D.F., N. N. Annie, D. M. Adelaide, S. Florian, and Inocent, G. 2010. Effect of heating and of short exposure to sunlight on carotenoids content of crude palm oil. J. Food Process Technol. Volume 5 Issue $4: 1-6$.

FDA. 2009. Food Drug Administration Advisory Committee on Protocols fos safety Evaluation: Panel on Reproduction Report on Reproduction Studies in Toxicology and Applied Pharmacology.16:264.

Fiskelova M., Silhar, S., Marecek, J., and Francakova, H. 2008. Extraction of carrot (Daucus carota L) carotenes under different condition. Journal Food Science 26(4): 268-274.

Gaziano, J. M. 1990. Beta carotene Therapy for November 1990. Dallas USA

Hutching, J. B. 1999. Food color and appearance 2 nd edition. A Chapman and Hall Food Science Book. Aspen Publication, Maryland.

Kartono D, Hardinsyah, Jahari A.B, Sulaeman A, Soekatri 2012. Penyempurnaan Kecukupan Gizi untuk Orang Indonesia. Widyakarya Nasional Pangan dan Gizi X, Jakarta:15-22

Klaui, H and Bauernfeind. J.C. 1981. Carotenoid as Food Colors in: Carotenoids as Colorants and Vitamin A Precursors. Academic Press, Inc. ISBN 0-12-082850-2: 48-168.5

Kusumaningtyas, R. S., dan Limantara, L. 2009. The isomerization and oxidation of carotenoid compounds in the oil palm fruit during production of CPO. Indo. J. Chem. 9(1):48-53.

Oktora, A.R., Ma'ruf, W.F., dan Agustini, T.W. 2016. Pengaruh penggunaan senyawa fiksator terhadap stabilitas ekstrak kasar pigmen $\beta$-karoten mikroalga Dunaliella salina pada kondisi berbagai suhu. JPHPI volume 19 nomeor 3: 206-213. 
PORIM.1995. PORIM test methods. Palm Oil Research Institute of Malaysia. Ministry of Primary Industries, malasiya.

Manurung, H., dan Simanjuntak, R. 2017. Studi subtitusi terigu dengan pasta pisang awak (Musa paradisiacal var.awak) pada pembuatan mi basah. Visi No.1 Vol.25. : 2843-2851

Rymbai, H., Sharma, R. R., and M. Srivastav. 2011. Biocolorants and its implication in health and food industry- A review. International Journal of Pharma Tech Research. Vol.3, no.4

Safriani, N.,Moulana, R., dan Ferizal. 2013. Pemanfaatan Pasta Sukun (artocarpus altilis ) pada Pembuatan Mi kering. Jurnal Teknologi dan Industri Pertanian Indonesia. Vol (5) N0.2. Hal: 17-24

Schroeder, M. T., E. M. Becker and L. H. Skibsted.2006. Molekuler mechanism of antioxidant synergism of tocotrioenols and carotenoids in palm oil. J. Agric. Food Chem. 54:3445-3450.

Soekarto, S.T. 1985. Penilaian Organoleptik untuk Industri Pangan dan Hasil Pertanian". Bhatara Karya Aksara, Jakarta.

Sundram, K., R. Sambathamurthi, and Y. A. Tan. 2003. Palm Fruit Chemistry and Nutrition. Asia Pasific J. Clinical Nutrition,12 (3):355-362.

Suyanti. 2008. Membuat mi sehat. PT. Bina ilmu 